
Management Improvement During

SUBJECT AREAS: APPLIED MATHEMATICS

MATHEMATICS AND COMPUTING

SCIENTIFIC DATA

STATISTICS

Received

27 February 2013

Accepted

11 March 2013

Published

8 April 2013

Correspondence and requests for materials should be addressed to S.B. (s.bishop@ucl.ac. \title{
Economic Downturn
}

\author{
Boris Podobnik ${ }^{1,2,8}$, Belal E. Baaquie ${ }^{3}$, Steven Bishop ${ }^{4}$, Djuro Njavro ${ }^{2}$ \& Baowen Li B $^{5,6,7}$
}

\begin{abstract}
${ }^{1}$ Faculty of Civil Engineering, University of Rijeka, 51000 Rijeka, Croatia, ${ }^{2}$ Zagreb School of Economics and Management, 10000 Zagreb, Croatia, ${ }^{3}$ Department of Physics and Risk Management Institute, National University of Singapore, Singapore 117542, Republic of Singapore, ${ }^{4}$ Department of Mathematics, UCL, Gower Street, London, WC1E 6BT, UK, ${ }^{5}$ Department of Physics and Center for Computational Science and Engineering, National University of Singapore, Singapore 1 17456, Republic of Singapore, ${ }^{6}$ NUS Graduate School for Integrative Sciences and Engineering, National University of Singapore, Singapore 117456, Republic of Singapore, ${ }^{7}$ Center for Phononics and Thermal Energy Science, School of Physical Science and Engineering, Tongji University, 200092, Shanghai, China, ${ }^{8}$ Faculty of Economics, University of Ljubliana, 1000 Ljubljana, Slovenia.
\end{abstract}

In estimating how economic growth depends on various inputs, economists commonly use long periods of data encompassing both main extremes to fluctuations in the economy: recession and expansion. Here we focus on recession years because during expansion even countries with bad economic policies may experience large growth. Specifically, we study how growth depends on the proportion of public-sector workforce, $p$ and competitiveness, quantified by the Global Competitiveness Index, GCI. For the 2008-2011 economic downturn and for 57 countries, we find that the growth rate of GDP per capita, $g$, decreases with $p$, and increases with $\Delta G C I$. Further, more competitive countries attract more foreign direct investments per capita, $I$, than less competitive countries, where $I \propto G C I^{\alpha}$. We propose a production function, divided into the private and public sectors, where GDP depends on market capitalization, the public (private)-sector workforce, and competitiveness level, used to quantify the public sector efficiency.

E conomic crises result in devastating impacts including sharp market declines and huge job losses. How severely an economic crisis affects a particular country partially depends on the efficiency of the government management prior to crisis. It is reasonable to assume that corruption is more severe in a country with a large proportion of government employees $p$ than in a country with a small $p$ (corruption may be considered as social cancer, and in a human body, the smaller the area of the body affected by cancer, the better). The percentage of government employees varies substantially across the world, ranging from less than $3 \%$ in Singapore to more than $33 \%$ in Norway and Sweden ${ }^{1}$. Mainly due to corruption, the public sector is considered as less efficient than the private sector ${ }^{2}$. Motivated by the popular debate on the economic and political merits of government versus private ownership $\mathrm{p}^{3-5}$, analyzing government-owned companies, Ehrlich et al. $^{6}$ reported that the change from complete state ownership to private ownership in the long run increases productivity growth on average by between 1.6 to $2 \%$ a year and costs declines by 1.7 to 1.9 percent.

One would expect that the public sector efficiency becomes especially important during an economic crisis since during good years even countries with weak growth policies that use massive indebtedness to increase their GDP, such as Greece before 2007, may experience economic expansion. For example, we may compare Sweden and Greece as two countries that substantially vary in the perceived corruption and competitiveness levels, both measures widely used to account for the difference in efficiency of the public sectors. Yet, during the 2008-2011 period, comprising recession years, Sweden considered as an un-corrupt country despite having $33 \%$ of government employees has increased its GDP per capita by approximately $4 \%$ (corrected for inflation), while Greece considered as a more corrupt country with smaller percentage of government employees, $23 \%$, has decreased its GDP per capita by approximately $21 \%$. This example qualitatively suggests that, generally, country $A$ with a large public sector can be even more successful than country $B$ with a smaller public sector, if country $A$ is characterized by a substantially smaller level of corruption or substantially larger level of competitiveness than country $B$. However, this begs the question of how we can quantify by how much country $A$ has to be less corrupt, or more competitive than country $B$, in order to be more successful? Therefore when we quantitatively evaluate the public 
sector in a given country, the size of the public sector should always be compared with its efficiency which can be estimated by the country's level of either corruption or competitiveness.

Here we study how the percentage of public sector employees and improvements of a government's institutions affect the growth rate of a country's wealth during economic crisis, specifically during 2008-2011. Firstly, we find that the growth rate of GDP per capita was substantially larger in countries with a smaller percentage of government employees than in countries with larger percentages of government employees. We report two valuable results for public management: a country significantly increases its growth rate of GDP per capita by improving its competitiveness, and more competitive countries attract more foreign direct investments per capita than less competitive countries. Finally, to aid modelling we include public and private sector efficiency through the country's level of either corruption or competitiveness in a macroeconomic production function.

\section{Results}

Empirical study. We quantify the performance of the public sector by two measures: by a country's competitiveness, measured by the Global Competitiveness Index, $G C T^{7}$ (see Fig. 1) and by a country's corruption level, measured by the Corruption Perception Index $(C \equiv$ $C P I$ ), defined by the Transparency International (see Data and Methods $)^{8-12}$. By definition, corruption is associated with only the public sector ${ }^{8,13-15}$. Note that the larger the value of $C$, the smaller the corruption in a country. Recently Davis et al. ${ }^{16}$ reported significant and positive benefits from privatization. They indicated a high correlation between privatization and growth. In a sample of 18 countries reviewed, they reported that governments tend to be financially better off after privatization than before. Sheshinski and Lopez-Calva ${ }^{17}$ also find that privatization improves the public sector's financial health. Privatization, by definition, reduces the percentage of public sector employees.

One may argue that one of the main reasons why privatization and growth are correlated is because of corruption. We may hypothesize that in a country with no corruption, the public and private sectors should be equally efficient. However, for countries that are corrupt we may expect that during a financial crisis, the largest drop in GDP per capita will occur, due to corruption, in countries with a large percentage of public sector employees. In order to check how the private and public sectors fare during financial crises, in Fig. 2(a) for

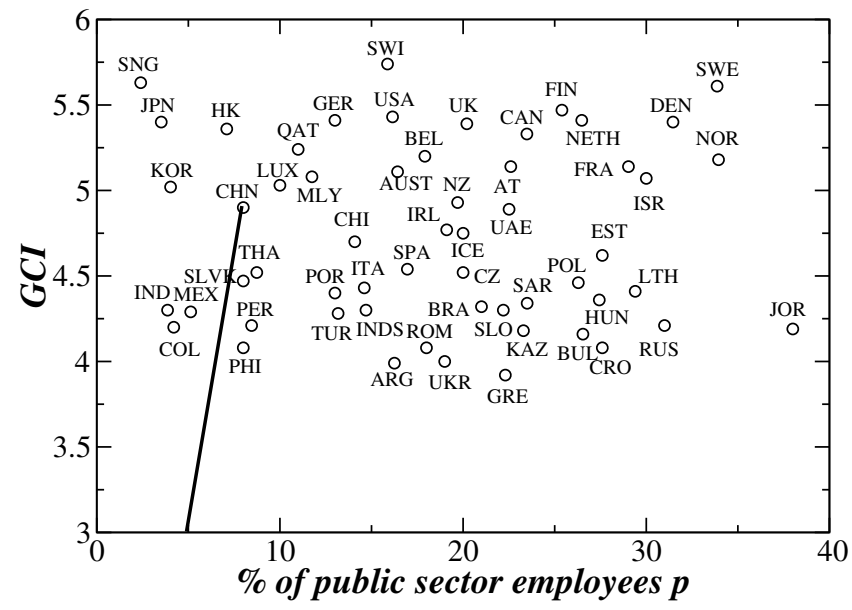

Figure 1 Competitiveness, quantified by the Global Competitiveness Index, GCIversus levels of public sector workforce in 2010. When we pick up a given country in the plot, we draw a line going through the origin and a dot given by the pair ( $p, \mathrm{GCI}$ ) (shown is China). Generally, the larger the slope, the better the country's performance.
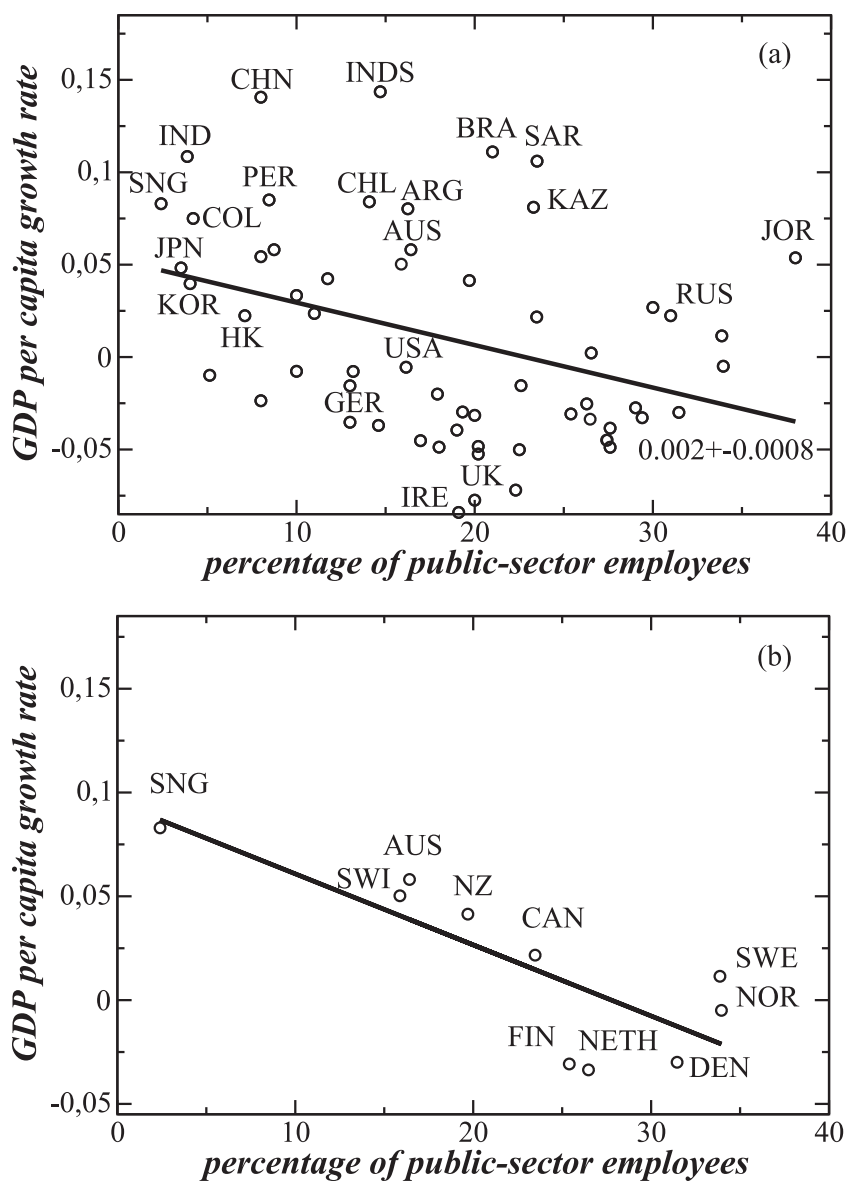

Figure 2 | Growth during 2008-2011 versus levels of public sector workforce in 2010. If the public sector was equally efficient to the private sector, the slope would be zero. (a) Countries with less public sector employees have larger increase in GDP per capita. With increasing the percentage of public sector employees the growth rate of GDP per capita decreases. (b) The same as in (a) but for the least corrupt countries. Data are in current U.S. dollars.

57 countries-ranging from undeveloped to developed for which we have public sector data-we show the growth rate of GDP per capita over 2008-2011 versus the percentage of workers in the public sector in $2010^{1}$. In Fig. 2(a) we find a decreasing functional dependence with the slope $0.002 \pm 0.0008$ obtained by using the least square fit. This finding indicates that increasing the percentage of workers in the public sector, the growth rate of GDP per capita generally decreases, implying that decreasing the percentage of workers in the public sector generally improves the country wealth.

In order to test our hypothesis that, for a country with no corruption, the public and private sectors are equally efficient, next in Fig. 2(b) for the 10 least corrupt countries in the World in 2010 we show the growth rate of GDP per capita, $g$, over 2008-2011 versus the percentage of workers in the public sector in $2010^{1}$. The $C$ level ranges between 9.3 (Singapore, Denmark, New Zealand) to 8.6 (Norway). It is clear that even for the set of least corrupt countries in the world, $g$ decreases with increasing the percentage of workers in the public sector. In Fig. 2(b) we obtain virtually the same slope $0.003 \pm$ 0.0009 as in Fig. 2(a) which we obtained for 57 countries. Note that, as stated in the Introduction, the difference in the value of the percentage of workers in the public sector between these countries is substantial-while in 1995 the Nordic countries had more than 30\% employees in their public sector, Singapore had less than 3\%. Thus, we obtain that even for the limit when $C$ tends to its maximum level 
$(C=10)$, countries with a smaller public sector perform better than countries with larger public sector workforce. Since we mainly relate the public sector with socialism and the private sector with capitalism, from the results reported in Fig. 2 we may conclude that a saying "Saving Capitalism from the Capitalists" should be extended to a similar saying "Saving Socialism from the Socialists".

Next we study changes in growth rates of a country's wealth as the result of changes in institutions ${ }^{9,18}$, quantified by changes either in competitiveness $^{7}$ or corruption ${ }^{12}$. First we study the case when changes in a country's institutions are accomplished through improvements in competitiveness, where we quantify competitiveness by $G C I$ - the larger the value of GCI, the larger the country's competitiveness. Clearly, it would be useful to study how improvements in competitiveness in one decade affect the growth in the following decade. However, the GCI was introduced in 2005 but the causal relationship would allow us to study, for example, how improvements in competitiveness during 2005-2008 affect the growth for the period 2008-2011. Generally, we do not expect significant changes in competitiveness over only a 3 -year period, since it takes longer for a country to substantially change the competitiveness level. Here we study how the change in competitiveness, $\triangle G C I$, for the period 2005-2011, affects the growth rate of GDP per capita for the period 2008-2011 (see Data and Methods). In Fig. 3(a) we report a clear increasing linear functional dependence between the annualized growth rate of GDP per capita calculated over the period 2008-2011, covering the recession years, and the change in competitiveness, $\Delta G C I$, for the period 2005-2011. Using a least-squares method, we obtain a positive and significant slope given by $0.12 \pm$
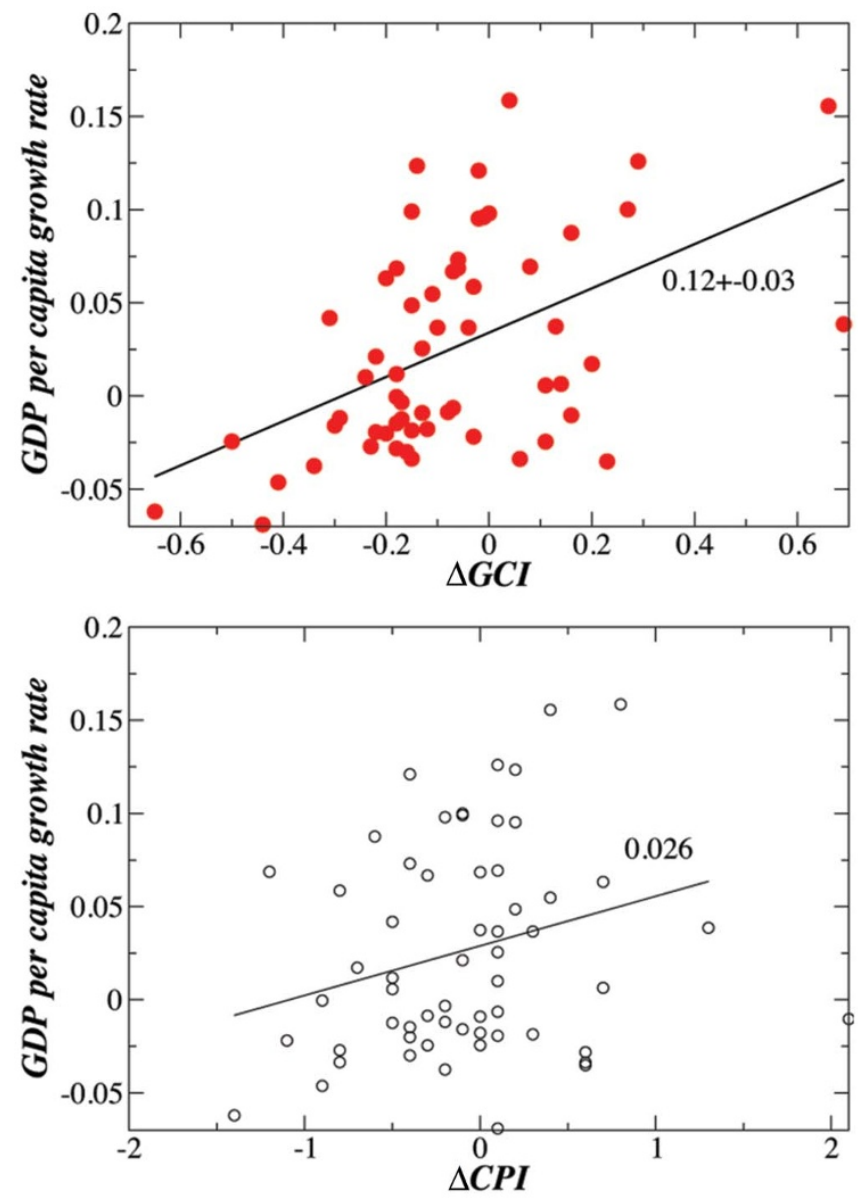

Figure 3 Improvements in institutions quantified by changes in (a) competitiveness and (b) corruption yield the increase in the growth rate of the annualized GDP per capita.
0.03. The increasing functional dependence in Fig. 3(a) clearly quantifies that improvements in public management, here measured by $G C I$, yield higher growth rates. Note that the large value for the slope is meaningful-according to GCI values for 2011, a unit change in $G C I$ is virtually the difference between the Russian $G C I$ (4.21) and the French GCI value (5.14), or between the Bangladesh GCI (3.73) and the Irish GCI value (4.77).

Next we note that Shleifer and Vishny ${ }^{19}$ argued that corruption would lead to lower economic growth. In order to quantify this assertion during an economic crisis, in Fig. 3(b), we replace the competitiveness index GCI by the corruption index, CPI (see Data and Methods), which is another measure for the quality of a country's institutions. Note again that the larger CPI, the smaller the country's corruption. We again report a increasing linear functional dependence but this time between the annualized growth rate of GDP per capita and the the annualized change in a country's corruption, $\triangle C P I$, during 2005-2011. We obtain a positive but insignificant slope equal to $0.026 \pm 0.014$, implying that improvement in institutions $(C P I>0)$, in this case reducing the corruption level, yields an increase in the growth rate of GDP per capita-the larger the decrease in the corruption level, the larger the increase in the growth rate of GDP per capita.

The results presented in Figs. 3 obviously show that improvements of a government's institutions, for a given country, are generally followed by an increase in the country's wealth. From the slopes obtained in Fig. 3(a) and Fig. 3(b) we surprisingly conclude that a country can significantly increase its growth rate of GDP per capita by improving its competitiveness rather than by reducing corruption. At the world level, for example China is ranked much higher according to competitiveness ranking than according to corruption ranking. Here we point out that $C P I$ is defined between 0 and 10 while $G C I$ is defined between 0 and 6 implying that it is harder to accomplish one unit improvement for GCI than one unit improvement for $C P I$.

One of the main motivations for improving competitiveness in a given country is to attract more foreign investment, and thus to additionally boost the increase in $\mathrm{GDP}^{20}$. Mauro ${ }^{14}$ reported that corruption decreases investment, and lowers economic growth. In our manuscript we now study not corruption but competitiveness. During the years 2008-2011 covering a world recession, we analyze foreign direct investments (FDI) received by a given country from all other countries. We study 128 countries ranging from undeveloped to developed for which we have both FDI and GCI values. For each country we sum up the foreign direct investments and calculate the annualized per capita FDI, I. In Fig. 4(a) we show that the functional dependence between the $I$ and the competitiveness level measured by GCI exhibits a power-law behavior with a statistically significant scaling exponent of $8.5 \pm 0.7$.

For the same set of countries as studied in Fig. 4(a), in Fig. 4(b) we report a similar increasing power-law dependence between $I$ and the corruption level measured by CPI, with a slope of $2.8 \pm 0.5$. Note that a similar power-law dependence was found by Podobnik et al. ${ }^{11}$ by studying the link between I and CPI during "good" years, 1999-2004. Thus, during a financial crisis, more competitive (larger GCI), as well as less corrupt countries (larger $C P I$ ), attract more foreign investments per capita. Since the power-law slope obtained in Fig. 4(a) is much steeper than the slope obtained in Fig. 4(b), we find a new valuable result for public-management strategy-a country can increase its foreign direct investment much more by improving its competitiveness than by improving its corruption level, a result in agreement with Fig. 3(a) and Fig. 3(b). This result is not so strange because $G C I$ is a more comprehensive measure than $C P I$ - the GCI encompasses many macroeconomic and the business aspects of competitiveness into a single index. We further emphasize the link between capital and corruption by reporting in Fig. 5 the powerlaw dependence between market capitalization per capita and CPI 

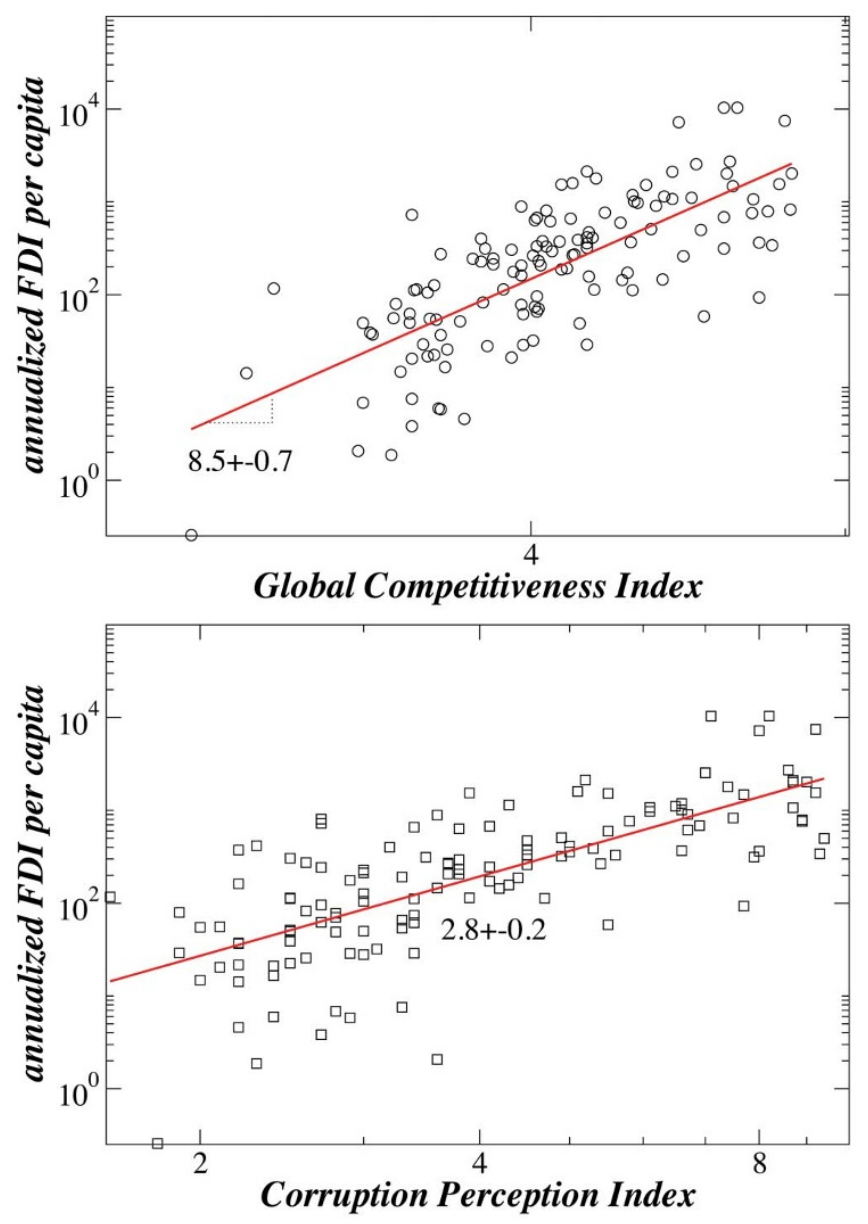

Figure $4 \mid$ Improvement of government management attracts more foreign investments. (a) More competitive countries receive more foreign direct investments per capita, $I$, than less competitive countries. (b) Less corrupt countries receive more $I$ than more corrupt countries.

for two different years, one before world recession and one during world financial crisis.

Modeling. There are two prevailing approaches in the theory of economic growth ${ }^{21-26}$, the neo-classical growth model ${ }^{27}$ and the endogenous growth model ${ }^{28,29}$. In the most popular neo-classical growth model, the Solow-Swan growth model, economic growth depends on increases in labor, capital and technical progress. In the macro-production function of the Solow-Swan model, $y=A k^{\alpha}$, that relates basic economic elements, $y$ represents the total income per worker in an economy, $A$ often represents technology, $k$ is the physical capital per worker, and $\alpha$ is a free parameter. In the endogenous growth models, besides physical capital, investment in human capital ${ }^{30}$, innovation, and education may also significantly contribute to economic growth.

To model how the percentage of public sector employees and improvements of government's institutions affect the growth rate of a country's wealth, as reported in Figs. 1-5, we start from the production function ${ }^{21,27,29}$ defined by Lucas ${ }^{29}$

$$
Y=A K^{\beta} H^{\gamma} L^{1-\beta-\gamma} \text {. }
$$

where income, $Y$, depends upon three input factors: labor, $L$, physical capital, $K$, and human capital, $H$, where $\beta$ and $\gamma$ are two parameters.

Next, in order to make a distinction between the private and public sectors, we extend the previous production function either by entering an economy's corruption level, $C \equiv C P I$, which is the average corruption level of its workers in public sector, or by entering an

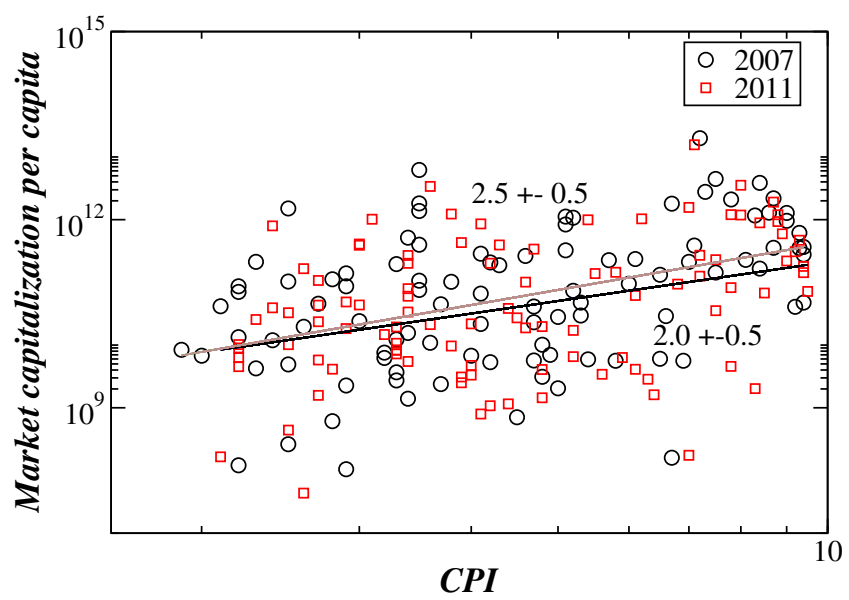

Figure 5 | Power-law dependence between per capita market capitalization and the level of corruption.

economy's competitiveness level, $C \equiv G C I$. Thus

$$
C=\left\{\begin{array}{ll}
C P I & \text { when corruption studied } \\
G C I & \text { when competitiveness studied }
\end{array} .\right.
$$

For simplicity, in the theoretical work hereafter we use $C \equiv C P I$.

We define an economy's income, $Y$, as a sum of its private and public parts. Therefore, we write

$$
Y=A L_{1}^{1-\beta-\gamma} K_{1}^{\beta} H_{1}^{\gamma}+A L_{2}^{1-\beta-\gamma} K_{2}^{\beta} H_{2}^{\gamma} E_{2} .
$$

In Eq. (3), the total capital is divided between its private, $K_{1}$, and public sector, $K_{2}$. Similarly, by $L_{1}\left(L_{2}\right)$ we denote the number of workers in the private (public) sector. By $H_{1}\left(H_{2}\right)$ we denote the total workers' human capital in the private (public) sector. As assumed in our model, $C \equiv C P I$, so by $E_{2}$ we denote a function of the level of corruption in the public sector, where it is assumed that $E_{2}=1$ denotes a country with no corruption, and $E_{2}=0$ denotes the most corrupt country. Note that if we use competitiveness to quantify public sector efficiency $(C \equiv G C I), E_{2}$ denotes a function of the level of competitiveness in the public sector, where $E_{2}=1$ denotes an ideal competitive country.

For the choice $C \equiv C P I$, we assume that $E_{2}$ can generally depend on both current and past values of the corruption index. Clearly one may argue that in a country with corruption, even the private sector is corrupt (but less than public sector), but for simplicity here we set $E_{1}=1$. Dividing $Y$ by $L=L_{1}+L_{2}$ we obtain the income per worker, $y$

$$
y=A \frac{L_{1}}{L} k_{1}^{\beta} h_{1}^{\gamma}+A \frac{L_{2}}{L} k_{2}^{\beta} h_{2}^{\gamma} E_{2} .
$$

Setting $p \equiv \frac{L_{2}}{L}$, then $100 p$ represents the percentage of employees in the public sector, and similarly, setting $(1-p) \equiv \frac{L_{1}}{L}, 100(1-p)$ represents the percentage of employees in the private sector.

Let us assume, due to lack of data, that the average physical capital and the average human capital are equal in both the public and private sectors which does not have to be met in real empirical data. One may expect that in corrupt countries less educated persons who have good connections can more easily get jobs than well educated persons with no connections. Thus, for simplicity and due to lack of data, setting $k_{1}=k_{2}$ and $h_{1}=h_{2}$ we obtain

$$
\begin{aligned}
y & =A(1-p) k^{\beta} h^{\gamma}+A p k^{\beta} h^{\gamma} E_{2} \\
& =A k^{\beta} h^{\gamma}\left[(1-p)+p E_{2}\right] .
\end{aligned}
$$

In the above equation, we expand the term $A k^{\beta} h^{\gamma}$ proposed by Lucas $^{29}$ by $G \equiv\left[(1-p)+p E_{2}\right]$ which we may call the efficiency gauge, where the larger it is, the better. Since, according to 
Transparency International, $C$ equal to 10 represents a country with no political corruption, by setting $E_{2}=C / 10$ we obtain

$$
y=A k^{\beta} h^{\gamma}[(1-p)+p(C / 10)]^{\rho},
$$

where, in analogy with the rest of the factors in the production function, we introduce a new parameter $\rho$. If say, a country wants to compare with Sweden, it should compare its efficiency gauge $G$ with Sweden's $(1-p)+p(C / 10)$. Recalling that the maximum $G C I$ index is 6 , note that if $E_{2}$ is based on a competitiveness and not on corruption, we can easily replace the corruption $C P I$ index by the competitiveness GCI index-more precisely in Eq. (6) we replace $C P I / 10$ by GCI/6. Finally we obtain the basic growth formula:

$$
\begin{aligned}
\Delta \ln (y)= & \Delta \ln (A)+\beta \Delta \ln (k)+\gamma \Delta \ln (h) \\
& +\rho \Delta \ln [(1-p)+p(C / 10)] .
\end{aligned}
$$

From Eq. (6) we note that in a corrupt country where $C<10$, the larger the proportion of workers in the public sector, $p$, the smaller the income per capita $y$. As an additional consequence, our model of Eq. (6) yields that in a country with no corruption $(C=10)$, it is irrelevant what the percentage of workers in the public and private sectors are, since $p+(1-p)(C / 10)=1$. No corruption implies no political corruption as well, and then both public and private sectors always employ the best candidates for any job, implying that the private and public sectors are doing equally well. As stated before, socialism is commonly related to the public sector and capitalism to the private sector, so our production function of Eq. (6) assumes that "socialism" ( $p=1)$ with ideal $C(C=10)$ is equally efficient to "capitalism" ( $p=0)$ in the world with no political corruption. However, this assumption is hardly in agreement with Fig. 2(b) where we showed that the growth rate of the 10 least corrupt countries in the world in 2008 versus the percentage of the public-sector workforce has a negative slope, significantly different from zero.

Hereafter we take GDP per capita as a proxy for income per capita. Next we study what our model predicts for changes in GDP per capita if either the proportion of workers in the public sector $p$ or the corruption (competitiveness) level changes. First, assuming only changes in $p$ and keeping all other variables constant, from Eq. (7) we obtain:

$$
\Delta \ln (y)=-\rho(1-[C / 10]) \Delta p .
$$

where for small values of $\mathrm{x}$, we use the following approximation $\ln (1+\mathrm{x}) \approx \mathrm{x}$. Clearly, as one would expect, the more corrupt a country is, the larger the change in GDP per capita, for a given change in $p$. Second, assuming only changes in $C P I(G C I)$, from Eq. (7) where again $\ln (1+\mathrm{x}) \approx \mathrm{x}$, we obtain:

$$
\Delta \ln (y)=\rho p \Delta[C / 10]
$$

As one would expect, the larger the public sector is, the unit change in CPI yields larger changes in GDP per capita. Alternatively, for a given country, the larger the value of $p$, the more important it is to fight corruption, since for a given $\Delta[C / 10], \Delta \ln (y)$ increases with $p$.

Our main goal in this study is to consider how the percentage of public sector employees and improvements of a government's institutions affect the growth rate of a country's wealth during the economic crisis of 2008-2011. More precisely, we study how a government management improvements and changes in market capitalization per capita affect the changes in GDP per capita. In order to estimate the model parameters in Eq. (6), first we find that for the public sector efficiency, GCI is the better estimator than CPI. Thus, in Eqs. (6)-(9) we replace CPI/10 by GCI/6. Next, since we have no data on human capital for the larger set of countries and different years, we disregard human capital in our study. However, our choice that $C \equiv G C I$ covers human capital to some extent, since the GCI depends on primary education, higher education and training (see Method section). Mankiw, Romer, and Weil assumed that
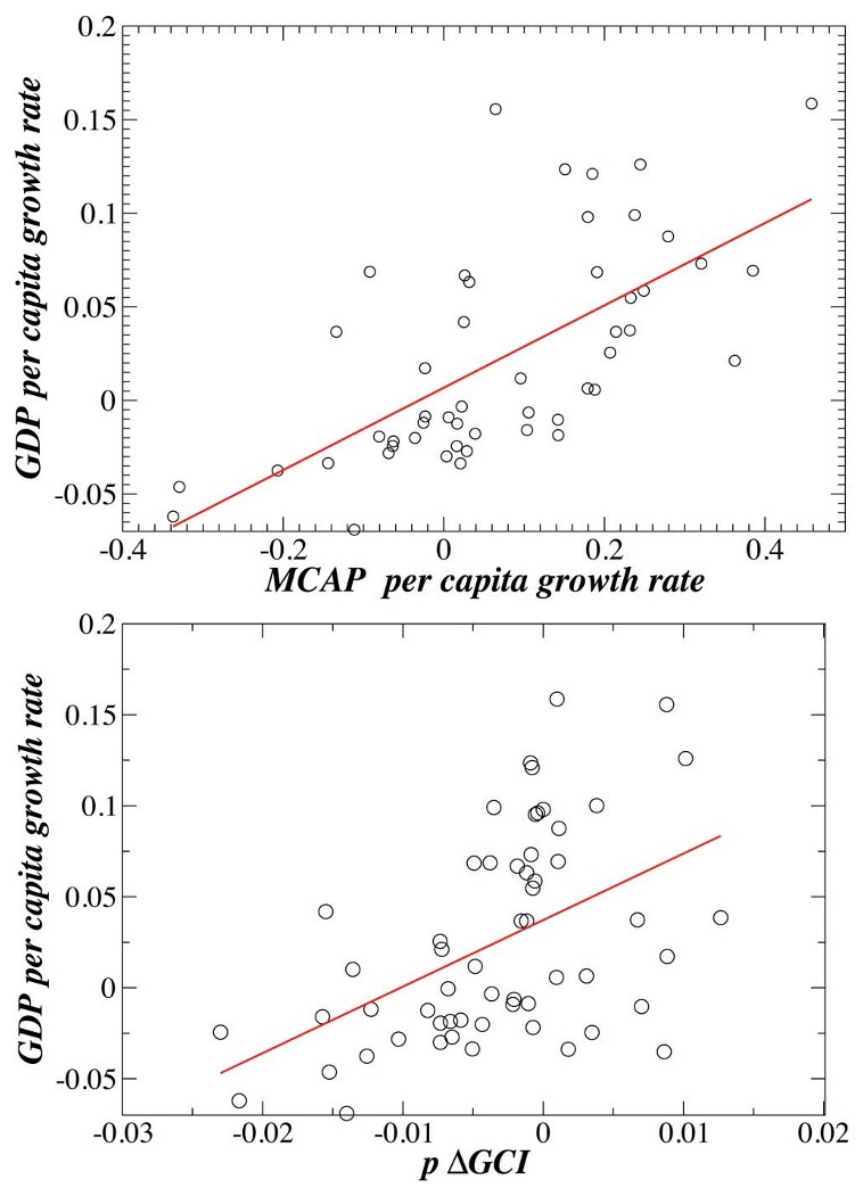

Figure $6 \mid$ (a) Growth rate of GDP per capita and growth rate of MCAP per capita follow each other and follow approximately a power law with average exponent close to 1/3. (b) Growth rate of GDP per capita versus public sector work force multiplied by changes in GCI.

the Solow model fits the empirical data better, once and additional variable-human capital- is introduced ${ }^{32}$. However, Islam ${ }^{33}$ reached an opposite conclusion, once a country's specific technological progress is introduced into the model ${ }^{33}$. We note that Benhabib and Spiegel ${ }^{30}$, based on a specific estimates on human capital, showed that human capital insignificantly explains per capita growth rates.

Next, due to lack of data for physical capital, we take market capitalization as a proxy for physical capital ${ }^{31}$, as more data is available. Avakian et al. ${ }^{31}$ analyzed over the 17-year period 1994-2010 the set of 68 countries for which there are published values of both GDP and MCAP, and reported that the GDP per capita, and the MCAP per capita, follow a power law with average exponent close to $1 / 3$. In Fig. 6(a) for 57 countries over 2008-2011, we show that the growth rates of $m$ and $g$ follow a slope $0.22 \pm 0.04$, not $1 / 3$ but not far from it.

Further, we assume that the public sector work force parameter $p$ for each country is constant, taken as it was recorded in $2010^{1}-$ according to OECD, since in 1995 the percentages of the labor force working for governments have been relatively stable in a large majority of countries ${ }^{35}$. From Eq. (6) using the approximation $\ln (1+\mathrm{x}) \approx$ $\mathrm{x}$, which holds when $\mathrm{x}$ is small, we estimate the equation

$$
\begin{aligned}
\left.\Delta \log \left(y_{i, t}\right)\right) & \equiv \log \left(y_{i, t+\Delta t} / y_{i, t}\right) \\
& =\ln (A)+\beta \log \left(m_{i, t+\Delta t} / m_{i, t}\right)+\rho p(\Delta G C I / 6),
\end{aligned}
$$

where $y$ stands for GDP per capita ${ }^{34}, m$ stands for market capitalization per capita ${ }^{34}, t$ stands for the time $t=2008$ and $\Delta t=3$ years. We use the set of 57 countries for which there are recorded values of GDP, MCAP, $p$, and GCI. As argued before, since GCI does not 
change substantially over three years, and we assume that $E_{2}$ in Eq. (5) depends on both current and past values of GCI, we calculate $\Delta G C I$ between 2005 and 2011. Thus, we assume that per capita GDP over 3 years changes due to changes in GCI over the last six years.

In Table 1 we report the model estimates together with the errors. In the second row we show the model estimates obtained for two simple regressions, the growth rate of GDP per capita versus the growth rate of MCAP per capita (see Fig. 6(a)), and separately the growth rate of GDP per capita versus $\rho p(\Delta G C I / 6)$ (see Fig. 6(b)) which is the second term in Eq. (10). Here we note that when two separate simple regressions are replaced with one unique multiple regression of Eq. (10), the influence of MCAP on GDP per capita is decreased while the influence of change in competitiveness (improvement in management) on GDP per capita is increased. In Table 2 we report that residuals show neither serial correlations nor heteroscadasticity. We also apply the variance inflation factor (VIF) to test the existence of multicollinearity between the variables in a multiple regression and show no multicollinearity.

Can we explain the difference in GDP per capita between, say, Sweden and Greece by comparing the size of their public sectors with the country's level of competitiveness? Going back to the last term in Eq. (6), comprising the efficiency gauge $\left[(1-p)+p E_{2}\right]$, next for 2010 we compare the Greek value $[(1-p)+p G C I / 6]^{\rho}=0.85^{6.5}$ $=0.35$ with the Swedish $[(1-p)+p G C I / 6]^{\rho}=0.98^{6.5}=0.88$, where we use $\rho=6.5$ (see Table 1 ). The values obtained for $[(1-p)+$ $p G C I / 6]^{\rho}, 0.35$ and 0.88 , are well in agreement with the GDP per capita of Greece and Sweden equal to $\$ 25,832$ and $\$ 49,360$, respectively ${ }^{34}$. Thus, in order to achieve the Swedish efficiency gauge level, Greece should substantially reduce either the public sector or increase its competitiveness level. Comparing a second pair of EU countries, Italy and Germany, Italy has approximately 19\% smaller GDP per capita than Germany. Again, for 2010 we compare the Italian's $[(1-p)+p G C I / 6]^{\rho}=0.96^{6.5}=0.77$ with the German's $[(1-p)+p G C I / 6]^{\rho}=0.99^{6.5}=0.94$. The ratio in the values of $[(1-$ $p)+p G C I / 6]^{\rho}$, equal to $22 \%$, is again in good agreement with the ratio obtained between the GDP per capita of Italy and Germany equal to $\$ 33,787$ and $\$ 40,164$, respectively ${ }^{34}$.

We also apply the regression of Eq. (10) for 6-year horizon between 2005 and 2011, including both recession and expansion years. We obtain that the second term shows no significance and we believe there are two reasons for this result. First, it is reasonably to assume that growth in GDP per capita for that period depends also on changes in GCI in the previous years and we have no GCI values before 2005. Second, it is very likely that in years of expension many countries grow even faster than they deserve, while in recession years large growth is expected either for countries with sigificantly large $G C I$ or for countries which sigificantly improved their $G C I$ values. So, the growth dynamics between 2005 and 2011 is too under the influence of the first subperiod characterized by expansion years.

Note that up to now our model assumes that for a country with no corruption $(C=10)$, the percentage of workers in the public and private sectors is irrelevant since in Eq. (6) $p+(1-p)(C / 10)=1$. However, one may assume that even in this limit when $C=10$, the private sector should outperform the public sector. In order to take this assumption into account, we next expand the production function with a new parameter $b<1$ that enables the private sector to

Table 1 | Estimates of parameters obtained for 57 countries, both corrupt/competitive and not corrupt/competitive. Student t-values are given in parentheses. In the second row we show the estimates obtained for two separate regressions of Eq. (8) and Eq. (9)

$\beta$

$\rho$

$0.21(5.55)$

$6.47(2.52)$

$3.66(4.10)$
Table 2 | Basic statistic for multiple regression. F test is used to compare the explained to the unexplained variance for 3 parameters estimated. BP test has null hypothesis of homoscadasticity. DW test has null hypothesis of no correlations. VIF test of multicolinearity indicates no multicolinearity between the variables in multiple regression. A VIF of 5 or 10 and above indicates a multicollinearity problem

\section{$R^{2}: 0.426$}

Adjusted $R^{2}: 0.405$

F-statistic: 20.06 on 2 and 54 DF, p-value: $3 . e-07$

Breusch-Pagan test: 2.27, p-value 0.132

Durbin-Watson test: 1.99, p-value 0.468

VIF $=1.206$

outperform the public sector even when $C$ tends to 10 . Here we write

$$
y=A k^{\beta} h^{\gamma}[(1-p)+p b(C / 10)]^{\rho} .
$$

Even when $C$ is equal to 10 , since $b<1$, then $(1-p)+p b(C / 10)=$ $(1-p)+p b \leq 1$, where equality holds when there is only the private sector $(p=0)$.

\section{Discussion}

During the 2008-2011 economic downturn, we reported here that (a) countries with a smaller percentage of workers in the public sector had larger growth rate in GDP per capita than countries with larger percentage of workers in the public sector. We also reported (b) an obvious increasing linear dependence between the growth rate of GDP per capita and the change in competitiveness, quantified by Global Competitiveness Index. Both (a) and (b) are potentially valuable results for public and government management. We also reported that (c) more competitive countries attract more annualized foreign direct investments per capita, $I$, than less competitive countries, where we reported a power law between $I$ and GCI. Changes in market capitalization, along with improvements in government management quantified by the changes in competitiveness, successfully describe the changes in GDP per capita during 2008-2011 economic downturn.

Note that recently some studies ${ }^{36}$ investigated public-private pay using French, British and Italian data. They show that in all countries the public sector on average pays more than the private sector, where the public sector is found to pay more for low skilled workers, whilst the reverse is true for high skilled workers. The effects are more pronounced for females. These discrepancies for low skilled workers are not in agreement with common sense and economic theory where higher risk (more likely to lose their job) is associated with the private sector and must be followed by higher reward (salary). In many European countries for example, social rights of employees working for the government are larger than the social rights of workers in the private sector. Both discrepancies can be an important trigger for the emergence of corruption. Besides these discrepancies we must point out that salaries in France are consistently higher than in Germany by $20-30 \%$ which is unsustainable in the long run since GDP per capita in these countries is similar while corruption in France is even higher than in Germany.

\section{Methods}

We study the Corruption Perception Index (CPI), measured by Transparency International in order to quantify the level of corruption in countries worldwide ${ }^{10,12}$ The larger the $C P I$, the smaller the level of corruption where $C P I=10$ means a country has no corruption. Since 2013 the CPI uses just one year of data from each source for each country. Previously the CPI had included the past two years of business survey data. Since political corruption is defined as misuse of public power and so is always related to the public sector. We note that the private sector itself might benefit greatly from crony capitalism as was the case of the US $\$ 2$ trillion bail out of banks by the US in 2008. This would mean that the corruption index $C$ is insufficient since it does not taken into account crony capitalism in the 
Anglo-American economies. However, here we use CPI as the level of corruption in a given country.

We also study the Global Competitiveness Index (GCI), which quantifies the institutions, policies, and factors that control economic prosperity ${ }^{7}$. It provides a raw score that ranges between 0 and 6 , where the later value defines the most competitive country. Since 2005, the World Economic Forum the GCI as "a comprehensive tool that measures the microeconomic and macroeconomic foundations of national competitiveness" . Competitiveness is defined "as the set of institutions, policies, and factors that determine the level of productivity of a country". There are 12 different determinants driving both productivity and competitiveness: the institutional environment, extensive and efficient infrastructure, macroeconomic environment health and primary education, higher education and training, goods market efficiency, labor market efficiency, technological readiness, financial market development, market size, business sophistication, and technological innovation. Note that the institutional environment includes government attitude towards markets and freedom and the efficiency of its operations comprising excessive bureaucracy and red tape, over-regulation, corruption, dishonesty in dealing with public contracts, and lack of transparency. Thus, GCI is more comprehensive index than CPI where fighting corruption is one of many GCI determinants.

In the paper we studied the following 57 countries: Argentina, Australia, Austria, Belgium, Brazil, Bulgaria, Canada, Chile, China, Colombia, Croatia, Czech R. Denmark, Estonia, Finland, France, Germany, Greece, Hong Kong, Hungary, Iceland, India, Indonesia, Ireland, Israel, Italy, Japan, Jordan, Kazakhstan, Korea R., Lithuania, Luxembourg, Malaysia, Mexico, The Netherlands, New Zealand, Norway, Peru, Philippines, Poland, Portugal, Qatar, Romania, Russia, Singapore, Slovakia, Slovenia, South Africa, Spain, Sweden, Switzerland, Thailand, Turkey, UAE, UK, Ukraine, USA.

In the paper we studied how $\Delta G C I$, calculated for the period 2005-2011, affects the growth rate of GDP per capita for the shorter period 2008-2011. Thus, performing regressions we assumed that GDP at time $t$ depends not only on GCI at $t$ but also equally on $G C I$ at $t-1$. As a simple case, suppose $G D P(t)=a(G C I(t)+G C I(t-1))$, where $a$ is a constant. Then, $\Delta G D P(t) \equiv G D P(t)-G D P(t-1)=a(G C I(t)-G C I(t-2))$, implying that two year change in GCI affects one year change in GDP.

1. IMD World Competitiveness Yearbook 2007 (http://www.imd.org/)

2. Sobel, R. The Pursuit of Wealth, McGraw Hill, New York, USA 1999.

3. Zinnes, C., Eilat, Y. \& Sachs, Jeffrey. The Gains from Privatization in Transition Economies: Is Change of Ownership Enough? IMF Staff Papers 48, pp. 146 (2001).

4. La Porta, R., Lpez-de-Silanes, F. \& Shleifer, A. Investor Protection and Corporate Governance. J. Financ. Econ. 58, 3-27 (2000).

5. Megginson, W. L. \& Netter, J. M. From State to Market: A Survey of Empirica Studies on Privatization. Journal of Economic Literature 39, 321-389 (2001).

6. Ehrlich, I., Gallais-Hamonno, G., Liu, Z. \& Lutter, R. Productivity Growth and Firm Ownership: An Empirical Investigation. J. Polit. Econ. 102, 1006-1038 (1994)

7. Schwab, K. The Competitiveness Report 2011-2012 (World Economic Forum, Geneva, 2012).

8. Svensson, J. Eight Questions about Corruption. J. Economic Perspectives 19, 19 (2005).

9. Podobnik, B., Horvatic, D., Kenett, D. Y. \& Stanley, H. E. The competitiveness versus the wealth of a country. Sci. Rep. 2, 350 (2012).

10. Shao, J., Ivanov, P. C., Podobnik, B. \& Stanley, H. E. Quantitative relations between corruption and economic factors. Eur. Phys. J. B 56, 157 (2007).

11. Podobnik, B., Shao, J., Njavro, D., Ivanov, P. C. \& Stanley, H. E. Quantitative relations between corruption and economic factors. Eur. Phys. J. B 63, 547 (2008).

12. http://www.transparency.org/research/cpi/overview.

13. Wheeler, D. \& Mody, A. International investment location decisions: The case of U.S. firms. J. International Economics 33, 57 (1992).

14. Mauro, P. Corruption and Growth. Quarterly Journal of Economics 110, 681 (1995).

15. Wei, S. J. How Taxing Is Corruption On International Investors? The Review of Economics and Statistics 82, 1 (2000).
16. Davis, J., Ossowski, R., Richardson, T. \& Barnett, S. Fiscal and Macroeconomic Aspects of Privatization. IMF Occasional Paper No. 194. Washington D.C. International Monetary Fund (2000).

17. Sheshinski, E. \& Lopez-Calva, L. F. Privatization and Its Benefits: Theory and Evidence. Harvard Institute for International Development, Cambridge, MA. Mimeo (1998).

18. Jones, C. I. \& Romer, P. M. The New Kaldor Facts: Ideas, Institutions, Population, and Human Capital. American Economic Journal 2, pages 224-45 (2010).

19. Shleifer, A. \& Vishny, R. Corruption. Quarterly Journal of Economics CIX, 599-617 (1993)

20. Feldstein, M. \& Horioka, C. Domestic Saving and International Capital Flows. Economic Journal 90, 314-329 (1980).

21. Barro, R. J. \& Sala-i-Martin, X. X. Economic Growth MIT Press, Cambridge MA, USA 1994.

22. Barro, R. J. Economic growth in a cross section of countries. Quarterly Journal of Economics 106, 407 (1991).

23. Barro, R. J. \& Sala-i-Martin X. Convergence. Journal of Political Economy 100, 223 (1992).

24. Quah, D. Empirical cross-section dynamics in economic growth. European Economic Review 37, 426 (1993).

25. Sala-i-Martin, X. X. The classical approach to convergence analysis. Economic Journal 106, 1019 (1996).

26. Durlauf, S. N. Manifesto for a growth econometrics. Journal Econometrics 100, 65 (2001).

27. Solow, R. M. A contribution to the theory of economic growth. Quarterly Journal of Economics 70, 65 (1956).

28. Romer, P. M. Increasing Returns and Long Run Growth. Journal of Political Economy 94, 1002 (1986)

29. Lucas, R. E. Jr. Why Doesn't Capital Flow from Rich to Poor Countries? American Economic Review 80, 92 (1990).

30. Benhabib, J. \& Spiegel, M. M. Interpreting tests of the convergence hypothesis. Journal Monetary Economics 34, 143 (1994)

31. Avakian, A., Podobnik, B., Podobnik, M. \& Stanley, H. E. in preparation.

32. Mankiw, N. G., Romer, D. \& Weil, D. N. A Contribution to the Empirics of Economic Growth. Quarterly Journal of Economics 58, 407-437 (1992).

33. Islam, N. Growth Empirics: A Panel data Approach. Quarterly Journal of Economics 90, 1127-1170 (1995).

34. World Bank http://data.worldbank.org/indicator.

35. http://www.oecd.org/gov/43926778.pdf.

36. http://www.ecb.europa.eu/pub/pdf/scpwps/ecbwp1406.pdf.

\section{Acknowledgments}

We thank the Grant R-144-000-285-646 from the National University of Singapore for financial support and Z. Zheng for discussions.

\section{Author contributions}

B.P. performed analyses, and B.P., S.B., B.B. and B.L. discussed the results, and contributed to the text of the manuscript.

\section{Additional information}

Competing financial interests: The authors declare no competing financial interests.

License: This work is licensed under a Creative Commons

Attribution-NonCommercial-NoDerivs 3.0 Unported License. To view a copy of this license, visit http://creativecommons.org/licenses/by-nc-nd/3.0/

How to cite this article: Podobnik, B., Baaquie, B.E., Bishop, S., Njavro, D. \& Li, B. Growth Versus Government Management Improvement During Economic Downturn. Sci. Rep. 3, 1612; DOI:10.1038/srep01612 (2013). 